\title{
Ordered SBA-15 mesoporous silica with high amino-functionalization for adsorption of heavy metal ions
}

\author{
ZHANG Dan \& LI JunHua* \\ School of Chemistry and Environmental Engineering, Liaoning University of Technology, Jinzhou 121001, China
}

Received June 10, 2012; accepted August 24, 2012; published online November 28, 2012

\begin{abstract}
Surface $\mathrm{NH}_{2}$-functionalized SBA-15 mesoporous silica was synthesized using toluene diisocyanate (TDI) as a bridge molecule. First, the surface $\mathrm{Si}-\mathrm{OH}$ groups of SBA-15 were reacted with the -NCO groups of TDI. Then, the remaining unreacted -NCO groups of TDI were reacted with the $-\mathrm{NH}_{2}$ groups of ethylenediamine (EDA). Finally, the $\mathrm{NH}_{2}$-groups were successfully grafted onto the mesoporous SBA-15 surface by the above two-step method. XRD, $\mathrm{N}_{2}$ adsorption-desorption analysis, FT-IR, and ${ }^{29} \mathrm{Si}$ MAS NMR were used to identify the well-ordered structure and the successful incorporation of the $-\mathrm{NH}_{2}$ groups onto the surface of the synthesized materials. Characterizations revealed that such $-\mathrm{NH}_{2}$ grafting is an effective method to obtain a high loading of $-\mathrm{NH}_{2}$ groups onto the SBA-15. When subjected to toxic heavy metal ions in aqueous solution, the obtained $\mathrm{NH}_{2}$-functionalized SBA-15 showed very high adsorption rates $99.9 \%, 99.7 \%, 99.8 \%, 99.5 \%$ and $99.9 \%$ for $\mathrm{Pb}^{2+}, \mathrm{Cr}^{3+}, \mathrm{Cd}^{2+}, \mathrm{Ag}^{+}$and the $\mathrm{Cu}^{2+}, \mathrm{re}^{-}$ spectively, which is attributed to the strong complexation reactions between the metal ions and the grafted $-\mathrm{NH}_{2}$ groups.
\end{abstract}

mesoporous silica, SBA-15, surface functional, amino

Citation: Zhang D, Li J H. Ordered SBA-15 mesoporous silica with high amino-functionalization for adsorption of heavy metal ions. Chin Sci Bull, 2013, 58: 879-883, doi: 10.1007/s11434-012-5594-0

Organically-functionalized mesoporous materials have generated considerable interest in their application in the fields of catalysis, and adsorption and separation processes, because they have a mechanically stable structure, high surface area, and large ordered pores with narrow size distributions. With attractive structural characteristics and excellent alkaline properties, amino-functionalized mesoporous silica had received increasing attention because of its potential applications, including adsorption of metal ions [1], protein sequestration and release [2], enzyme immobilization [3], drug delivery [4], and catalysis [5,6]. Traditionally, this kind of aminosilica material is synthesized primarily by two main strategies; one is the direct method [7-11], and the other is the post-synthesis method [12-15]. In a direct method, aminofunctionalized large-pore mesoporous materials were synthesized by co-condensation of tetraethoxysilane (TEOS) and aminosilanes. The advantage of the direct method is that amine groups can be easily incorporated into the

*Corresponding author (email: lijunhua0521@163.com) framework of mesoporous materials. However, disordered amino-functionalized mesoporous silica was obtained by the direct co-condensation method. As proposed by Zhao et al. [16], this is related to the unmatched hydrolysis rates between the aminosilane and TEOS, as well as the strong interference of the amine groups on the co-assembly process. To circumvent this "interference" problem, Wang et al. [7] and Wei et al. [17] successfully synthesized amine-functionalized SBA-15 with ordered large pores by pre-hydrolysis of the TEOS before the addition of aminopropyltriethoxysilane (APTES).

Despite considerable progress having been made for the one-pot synthesis of amino-functionalized mesoporous silica, approaches based on post-synthetic functionalization remain popular because the separation of the silica synthesis and functionalization steps allows an independent and more straightforward control of the pore size and periodicity. Therefore, the post-synthesis method could be favorable for the formation of well-ordered structures. But the amino chains that have been first grafted onto the mesoporous 
silica surface would form hydrogen bonding with the surface silanols, thereby preventing the further grafting of amino groups on the silica surface [18,19]. Zeng et al. [12] synthesized amine-functionalized mesoporous materials by a solvothermal process. Daehler et al. [14] synthesized surface amine-modified mesoporous silica via vapor-phase reactions. Much research has been focused on reducing amino-silanol and amino-amino interactions for the preparation of amino-functionalized SBA-15 with a high loading of amino groups [20,21].

It remains a challenge to synthesize amine-functionalized ordered mesoporous materials with large pores. In the present study, we proposed a novel method to synthesize aminofunctionalized SBA-15 (Figure 1). Herein, toluene diisocyanate (TDI) was employed as a "bridge" molecule whose one bridgehead group -NCO was used to link with an silanol group on the SBA-15 surface and the other was left to link with an amino group of ethylenediamine (EDA). Such a method should have a high linking efficiency because TDI is a very active molecule whose two - $\mathrm{NCO}$ groups can easily bond with $-\mathrm{OH}$ or $-\mathrm{NH}_{2}$ groups [22]. Meanwhile, the stepwise link can avoid the interactions between amino-silanol and amino-amino groups. Therefore, it would be useful to synthesize amino-functionalized SBA-15 with a high loading of amino groups. Moreover, the adsorption performance of the obtained material was investigated for the removal of heavy metal ions, $\mathrm{Pb}^{2+}, \mathrm{Cr}^{3+}, \mathrm{Cd}^{2+}, \mathrm{Ag}^{+}$and $\mathrm{Cu}^{2+}$, from waste water.

\section{Experimental}

\subsection{Preparation of surface $\mathrm{NH}_{2}$-functionalized SBA-15 mesoporous silica}

The preparation of amino-functionalized SBA-15 involved three steps. First, pure siliceous SBA-15 was prepared according to the reported literature $[23,24]$. Then, $1.0 \mathrm{~g}$ of assynthesized SBA-15 powder without templates was added into a mixed solution of $8.3 \mathrm{~mL}$ TDI and $16.7 \mathrm{~mL}$ of toluene. After stirring at $60^{\circ} \mathrm{C}$ for $5 \mathrm{~h}$, the powder (denoted as T-SBA-15) was filtered and Soxhlet-extracted with $\mathrm{CH}_{2} \mathrm{Cl}_{2}$ for $48 \mathrm{~h}$. At last, $1.0 \mathrm{~g}$ of dried T-SBA-15 powders was added into a mixed solution of $20.0 \mathrm{~mL}$ of ethylenediamine (EDA) and $20.0 \mathrm{~mL}$ of ether. The mixture was then stirred at $20^{\circ} \mathrm{C}$ for $24 \mathrm{~h}$, and the final powder (denoted as $\mathrm{NH}_{2}-$ SBA-15) was filtered, Soxhlet-extracted and dried.

\subsection{Adsorption experiments}

In a typical adsorption experiment, $20 \mathrm{~mL}$ of a single metal solution in a flask was mixed with $150 \mathrm{mg}$ of adsorbent at room temperature. After stirring while covered for $24 \mathrm{~h}$, the suspension was collected from the flask and centrifuged. The metal ion concentrations, both in the initial and final solutions, were determined by inductively-coupled plasmaatomic emission spectrometry (ICP-AES) on a TJA AtomScan16 spectrometer.

\subsection{Characterization of materials}

The powder X-ray diffraction (XRD) patterns were recorded on a Bruker diffractometer using $\mathrm{Cu} \mathrm{K} \alpha$ radiation. $\mathrm{N}_{2}$ adsorption-desorption isotherms were obtained on a Micromeritics Tristar 3000 pore analyzer at $77 \mathrm{~K} .{ }^{29} \mathrm{Si}$ MAS NMR experiments were performed on a Varian Infinityplus-300 spectrometer using a $7.5 \mathrm{~mm}$ probe under magicangle spinning: the resonance frequency was $79.5 \mathrm{MHz}$; the $90^{\circ}$ pulse width was measured to be $4.8 \mu \mathrm{s}$; a repetition time of $100 \mathrm{~s}$ for single-pulse experiments was used. FT-IR spectra were recorded on a Nicolet 470 Spectrometer with $4 \mathrm{~cm}^{-1}$ resolution. Thermogravimetric analysis (TGA) studies were performed from 30 to $1000^{\circ} \mathrm{C}$ using a PerkinElmer TGA7 instrument, coupled with a mass spectrometer for evolved gas analysis, under a helium atmosphere. The heating rate was $20^{\circ} \mathrm{C} / \mathrm{min}$, and the helium flow was approximately $100 \mathrm{~mL} / \mathrm{min}$.


( $\left.\mathrm{NH}_{2}-\mathrm{SBA}-15\right)$

Figure 1 Schematic illustration of the synthesis strategy of $\mathrm{NH}_{2}-\mathrm{SBA}-15$. 


\section{Results and discussion}

XRD patterns of three samples are presented in Figure 2. An intense peak (100) and two well-resolved small peaks (110) and (200) could be observed for all the samples, being indicative of well-ordered hexagonal mesoporous structures [12]. This result indicates that the mesoporous structure was not destroyed during the surface amino-functionalization process.

$\mathrm{N}_{2}$ adsorption-desorption isotherms and pore diameter distributions of the samples were also studied (see Figures 3 and 4). Three samples possessed typical Type IV isotherms and $\mathrm{H} 1$ hysteresis loops, further confirming the characteristics of the mesoporous materials [25]. In Figure 4, the pore diameters of three samples displayed the sequence: SBA-15 $(7.7 \mathrm{~nm})>\mathrm{T}-\mathrm{SBA}-15(6.6 \mathrm{~nm})>\mathrm{NH}_{2}-\mathrm{SAB}-15(5.3 \mathrm{~nm})$. The pore size distributions are calculated from the adsorption branch of the isotherm by the BJH method. This is an expected result, reflecting that the SBA-15 surface was indeed

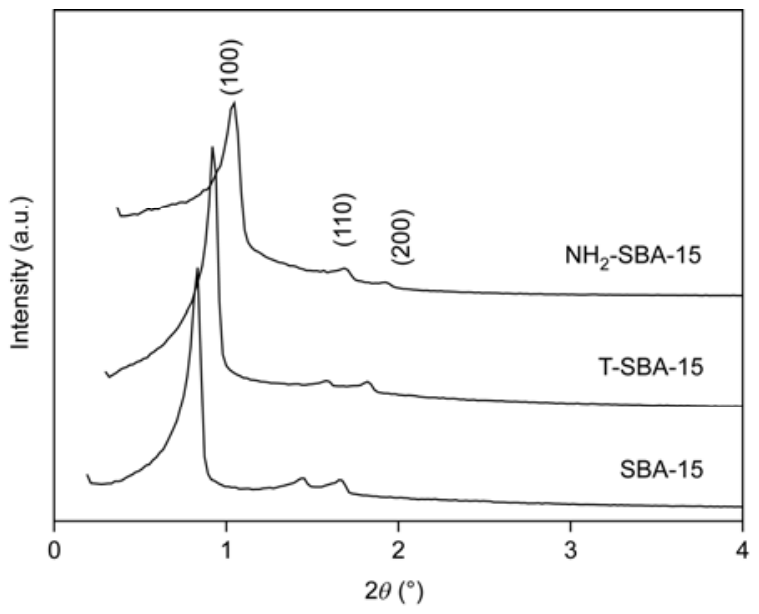

Figure 2 Powder X-ray diffraction patterns of SBA-15, T-SBA-15 and $\mathrm{NH}_{2}$-SBA-15.

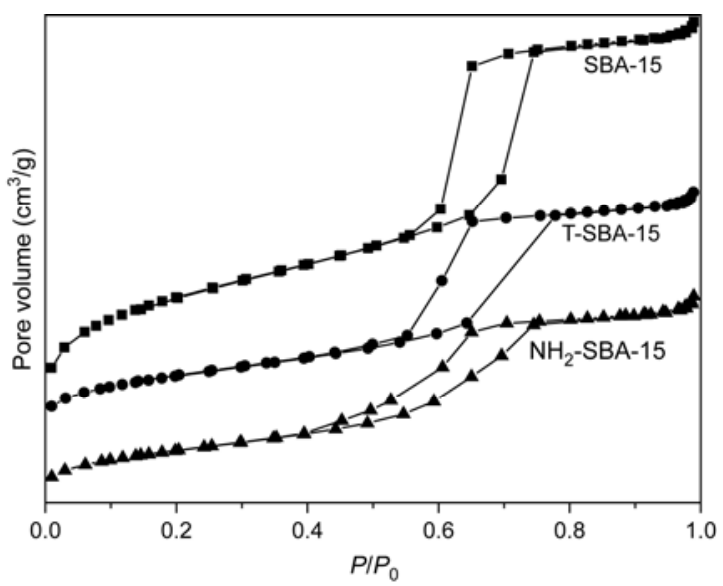

Figure $3 \mathrm{~N}_{2}$ adsorption and desorption isotherms of SBA-15, T-SBA-15 and $\mathrm{NH}_{2}-\mathrm{SBA}-15$.

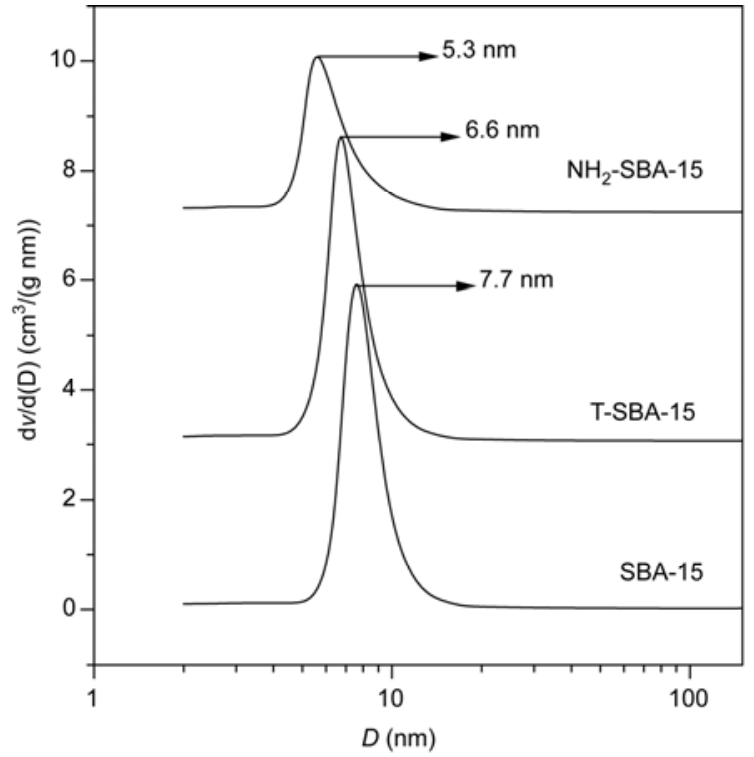

Figure 4 Pore size distribution of SBA-15, T-SBA-15 and $\mathrm{NH}_{2}-\mathrm{SBA}-15$

stepwise organic-functionalized. For T-SBA-15, the surface $\mathrm{Si}-\mathrm{OH}$ groups reacted with the -NCO groups of TDI, resulting in a pore size being smaller than that of SBA-15. As another -NCO group on the T-SBA-15 reacted with one $-\mathrm{NH}_{2}$ group of EDA, the pore size of $\mathrm{NH}_{2}-\mathrm{SBA}-15$ was smaller than that of T-SBA-15. At the same time, all three samples have a narrow pore size distribution, indicating that the mesoporous surfaces of T-SBA-15 and $\mathrm{NH}_{2}-\mathrm{SBA}-15$ have a uniformly functional surface coating.

FT-IR spectra of SBA-15, T-SBA-15 and $\mathrm{NH}_{2}$-SBA-15 were investigated (Figure 5). In the spectrum of the $\mathrm{T}$ SBA-15 sample, an adsorption peak at $2280 \mathrm{~cm}^{-1}$ attributable to the -NCO group of TDI could be observed [26]. This finding suggests that one end of the TDI molecules had been grafted onto the SBA-15 surface. For the $\mathrm{NH}_{2}-\mathrm{SBA}-15$ sample, the peak at $2280 \mathrm{~cm}^{-1}$ disappeared, to be replaced by two new adsorptions at 3186 and $3385 \mathrm{~cm}^{-1}$ being



Figure 5 FT-IR spectra of SBA-15, T-SBA-15 and NH $2-S B A-15$. 
attributable to the $-\mathrm{NH}_{2}$ groups of EDA [27]. These results indicated that EDA could be one-end grafted onto the SBA-15 surface using the TDI molecules as a "bridge". The concentration of free amine groups on the surface of $\mathrm{NH}_{2}-$ SBA-15 was determined by the acid titration method. The result showed that the concentration of free amine groups for $\mathrm{NH}_{2}$-SBA-15 was $0.00264 \mathrm{~mol} / \mathrm{g}$.

${ }^{29} \mathrm{Si}$ MAS NMR was used to determine the degree of TDI grafting on the SBA-15 surface. Figure 6 shows the ${ }^{29} \mathrm{Si}$ MAS NMR spectra of two of the three samples studied. The corresponding relative peak areas in ${ }^{29} \mathrm{Si}$ MAS NMR spectra are summarized in Table 1 . Therein, $\mathrm{Q}^{4}, \mathrm{Q}^{3}, \mathrm{Q}^{3^{\prime}}$ and $\mathrm{Q}^{2}$ respectively represent the silicon atom environments of $(\mathrm{SiO})_{4} \mathrm{Si}$, $(\mathrm{SiO})_{3} \mathrm{SiOH},(\mathrm{SiO})_{3} \mathrm{SiOTDI}$ and $(\mathrm{SiO})_{2} \mathrm{Si}(\mathrm{OH})_{2}$, in which $(\mathrm{SiO})_{3} \mathrm{SiOTDI}\left(\mathrm{Q}^{3^{\prime}}\right)$ indicates the link between the TDI molecule and the $\mathrm{Si}-\mathrm{OH}$ groups of $(\mathrm{SiO})_{3} \mathrm{SiOH}\left(\mathrm{Q}^{3}\right)$. It is well known that the transformation of $\mathrm{Si}-\mathrm{OH}$ groups into $\mathrm{Si}-\mathrm{OC}$ would result in the silicon atom undergoing a chemical shift toward the low field [28]. Nevertheless, in the ${ }^{29} \mathrm{Si}$ MAS NMR spectra of T-SBA-15, no new peaks appeared as compared with that of SBA-15. Moreover, the $\mathrm{Q}^{3}$ peak was no longer present. The reason for this result is expected to be that the transformation of $(\mathrm{SiO})_{3} \mathrm{SiOH}\left(\mathrm{Q}^{3}\right)$ into $(\mathrm{SiO})_{3^{-}}$ SiOTDI $\left(Q^{3^{\prime}}\right)$ was virtually complete, and the $Q^{3^{\prime}}$ peak appeared at the position well approximate to that of $\mathrm{Q}^{4}$. Through data fitting in Table 1 , it was found that both of SBA-15 and T-SBA-15 had almost equal $(\mathrm{SiO})_{2} \mathrm{Si}(\mathrm{OH})_{2}$ contents. This might be explained by the reported conclusion that it is difficult to organically functionalize the $\mathrm{Si}-\mathrm{OH}$ groups of $(\mathrm{SiO})_{2} \mathrm{Si}(\mathrm{OH})_{2}[16]$ because of the strong hydrogen-bonding interaction between the geminate $\mathrm{Si}-\mathrm{OH}$ groups of $(\mathrm{SiO})_{2} \mathrm{Si}(\mathrm{OH})_{2}$. Also in Table 1, the percent contents of surface $\mathrm{Si}-\mathrm{OH}$ groups were found to be $57.4 \%$ for SBA-15 and only $13.2 \%$ for TDI-SBA-15, indicating that the high degree of TDI grafting on the SBA-15 surface was realized.

Figure 7 shows the TG analysis curves for SBA-15, TSBA-15 and $\mathrm{NH}_{2}-\mathrm{SBA}-15$. For all of these samples, a slight weight loss was observed below $200^{\circ} \mathrm{C}$, which is ascribed to residual water. In addition, SBA-15 shows a slight weight loss between 200 and $600^{\circ} \mathrm{C}$ owing to the condensation reaction between the $\mathrm{Si}-\mathrm{OH}$ groups. In contrast, both T-SBA15 and $\mathrm{NH}_{2}$-SBA-15 exhibited considerable weight losses between 200 and $300^{\circ} \mathrm{C}$, which is considered to be caused by decomposition of the organic component. And, the weight loss of NH2-SBA-15 was $(19.9 \%)$, which is 1.32 times $(15.1 \%)$ that of T-SBA-15, in good agreement with the mo- lecular weight ratio 1.33 of (TDI+EDA) to TDI. Therefore, it could be concluded that each TDI molecule was grafted to the SBA-15 surface via one head group, and subsequently EDA was one-head grafted with the other head group of TDI.

The $\mathrm{NH}_{2}$-functionalized SBA-15 exhibited a unique affinity toward heavy metal ions. Table 2 shows the metal ion concentrations of simulated wastewater before and after adsorption by SBA-15, T-SBA-15 and $\mathrm{NH}_{2}-\mathrm{SBA}-15$. It can be seen that the SBA-15 adsorbent scarcely removed the heavy metal ions, $\mathrm{Pb}^{2+}, \mathrm{Cr}^{3+}, \mathrm{Cd}^{2+}, \mathrm{Ag}^{+}$and $\mathrm{Cu}^{2+}$, from the wastewater. After adsorption by T-SBA-15, the metal ion concentration decreased slightly. In contrast, the $\mathrm{NH}_{2}-\mathrm{SBA}-$ 15 adsorbent efficiently removed the heavy metal ions under the same conditions. The T-SBA-15 is able to adsorb some heavy metal ions because of the acylamide bonds after the surface $\mathrm{Si}-\mathrm{OH}$ groups of SBA-15 were reacted with one -NCO group of TDI. For the $\mathrm{NH}_{2}-\mathrm{SBA}-15$ adsorbent, the significant concentration changes are indeed attributed to the complexation reactions that occur between the metal ions and the grafted $\mathrm{NH}_{2}$ - groups.

\section{Conclusion}

In summary, well-ordered surface $\mathrm{NH}_{2}$-functionalized mesoporous silica SBA-15 was readily synthesized using a novel and effective method. This method employed TDI as the bridge molecule for this $\mathrm{NH}_{2}$-functionalization, and included the following remarkable advantages: (1) preventing amino-



Figure $6{ }^{29} \mathrm{Si}$ MAS NMR spectra of SBA-15 and T-SBA-15.

Table 1 Relative peak areas (\%) in ${ }^{29}$ Si MAS NMR Spectra of SBA-15 and T-SBA-15

\begin{tabular}{|c|c|c|c|c|c|}
\hline \multirow{2}{*}{ Samples } & \multicolumn{5}{|c|}{$\delta /$ relative peak area } \\
\hline & $\mathrm{Q}^{2}$ & $\mathrm{Q}^{3}$ & $\mathrm{Q}^{4}$ & $\mathrm{Q}^{3^{\prime}}+\mathrm{Q}^{4}$ & $\left(2 Q^{2}+Q^{3}\right)^{a)}$ \\
\hline SBA-15 & $-92.7 / 6.8 \%$ & $-102.4 / 44.2 \%$ & $-110.0 / 49.0 \%$ & - & $57.4 \%$ \\
\hline
\end{tabular}

a) Represents the percent content of surface $\mathrm{Si}-\mathrm{OH}$ groups. 


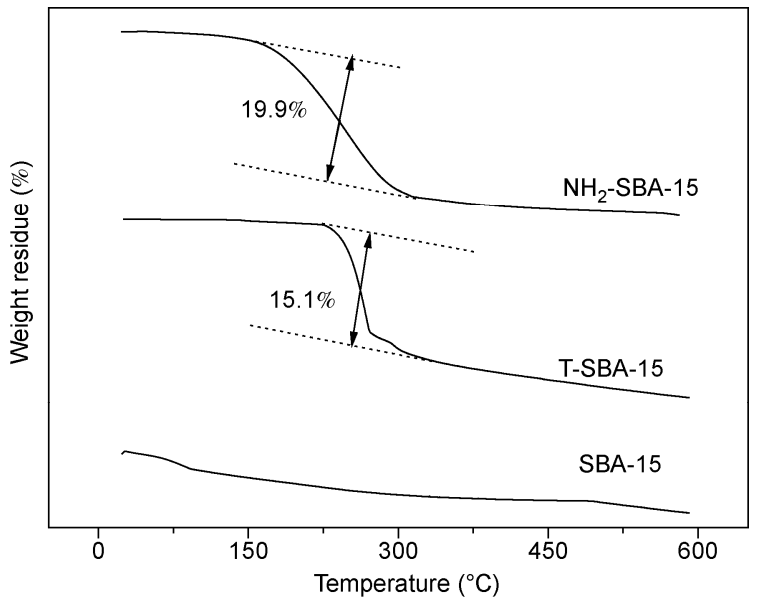

Figure 7 TGA thermograms of SBA-15, T-SBA-15 and $\mathrm{NH}_{2}$-SBA- 15 .

Table 2 Concentrations of heavy metal ions in water before and after adsorbed (unit: $\mathrm{mg} / \mathrm{L}$ )

\begin{tabular}{|c|c|c|c|c|c|}
\hline Solution & $\mathrm{Pb}^{2+}$ & $\mathrm{Cr}^{3+}$ & $\mathrm{Cd}^{2+}$ & $\mathrm{Ag}^{+}$ & $\mathrm{Cu}^{2+}$ \\
\hline Before adsorbed & 9.79 & 9.12 & 10.13 & 9.81 & 9.57 \\
\hline $\begin{array}{l}\text { After adsorbed by } \\
\text { SBA-15 }\end{array}$ & 9.73 & 9.12 & 10.01 & 9.72 & 9.49 \\
\hline $\begin{array}{l}\text { After adsorbed by } \\
\text { T-SBA-15 }\end{array}$ & 7.59 & 8.03 & 8.32 & 8.16 & 8.01 \\
\hline $\begin{array}{l}\text { After adsorbed by } \\
\mathrm{NH}_{2} \text {-SBA- } 15\end{array}$ & 0.011 & 0.025 & 0.019 & 0.052 & 0.008 \\
\hline $\begin{array}{l}\text { Adsorption rate on } \\
\mathrm{NH}_{2} \text {-SBA-15 }\end{array}$ & $99.9 \%$ & $99.7 \%$ & $99.8 \%$ & $99.5 \%$ & $99.9 \%$ \\
\hline
\end{tabular}

silanol and amino-amino interactions occurring; (2) preventing destruction of the mesoporous structure; (3) providing high functional efficiency. As expected, a high loading of amino groups on the SBA-15 surface was realized. The obtained material showed a high adsorption capacity for heavy metal ions due to the strong complexation reactions that occur between metal ions and the grafted $-\mathrm{NH}_{2}$ groups.

1 Liu A M, Hidajat K, Kawi S, et al. A new class of hybrid mesoporous materials with functionalized organic monolayers for selective adsorption of heavy metal ions. Chem Commun, 2000, 13: 1145-1146

2 Han Y J, Stucky G D, Butler A. Effect of hexafluoroisopropanol on the thermodynamics of peptide secondary structure formation. J Am Chem Soc, 1999, 121: 9879-9880

3 Descalzo A B, Jimenez D, Marcos M D, et al. A new approach to chemosensors for anions using MCM-41 grafted with amino groups. Adv Mater, 2002, 14: 966-969

4 Balas F, Manzano M, Horcajada P, et al. Confinement and controlled release of bisphosphonates on ordered mesoporous silica-based materials. J Am Chem Soc, 2006, 128: 8116-8117

5 Sharma K K, Asefa T. Efficient bifunctional nanocatalysts by simple postgrafting of spatially isolated catalytic groups on mesoporous Materials. Angew Chem Int Ed, 2007, 46: 2879-2882

6 Macquarrie D J, Jackson D B. Aminopropylated MCMs as base catalysts: A comparison with aminopropylated silica. Chem Commun, 1997, 18: 1781-1782
7 Wang X G, Lin K S K, Chan J C C, et al. Preparation of ordered large pore SBA-15 silica functionalized with aminopropyl groups through one-pot synthesis. Chem Commun, 2004, 23: 2762-2763

8 Zhang L, Liu J, Yang J, et al. Direct synthesis of highly ordered amine-functionalized mesoporous ethane-silicas. Microporous Mesoporous Mat , 2008, 109: 172-183

9 Zhang W H, Lu X B, Xiu J H, et al. Synthesis and characterization of bifunctionalized ordered mesoporous materials. Adv Funct Mater, 2004, 14: 544-552

10 Chong A S M, Zhao X S. Functionalization of SBA-15 with APTES and characterization of functionalized materials. J Phys Chem B, 2003, 107: 12650-12657

11 Mouawia R, Mehdi A, Reye C, et al. Bifunctional ordered mesoporous materials direct synthesis and study of the distribution of two distinct functional groups in the pore channels. J Mater Chem, 2008, 18: 4193-4203

12 Zeng W, Qian X F, Zhang Y B, et al. Organic modified mesoporous MCM-41 through solvothermal process as drug delivery system. Mater Res Bull, 2005, 40: 766-772

13 Zheng S, Gao L, Guo J K. Synthesis and characterization of copper(II)phenanthroline complex grafted organic groups modified MCM-41. Mater Chem Phys, 2001, 71: 174-178

14 Daehler A, Boskovic S, Michelle L, et al. Postsynthesis vapor-phase functionalization of MCM-48 with hexamethyldisilazane and 3aminopropyldimethylethoxylsilane for bioseparation applications. J Phys Chem B, 2005, 109: 16263-16271

15 Ritter H, Nieminen M, Karppinen M, et al. A comparative study of the functionalization of mesoporous silica MCM-41 by deposition of 3 -aminopropyltrimethoxysilane from toluene and from the vapor phase. Microporous Mesoporous Mat, 2009, 121: 79-83

16 Chong A S M, Zhao X S, Kustedjo A T, et al. Functionalization of large-pore mesoporous silicas with organosilanes by direct synthesis. Microporous Mesoporous Mat, 2004, 72: 33-42

17 Wei Q, Nie Z R, Hao Y L, et al. Effect of synthesis conditions on the mesoscopical order of mesoporous silica SBA-15 functionalized by amino groups. J Sol-Gel Sci Technol, 2006, 39: 103-109

18 Hicks J C, Jones C W. Controlling the density of amine sites on silica surfaces using benzyl spacers. Langmuir, 2006, 22: 2676-2681

19 Perrin C L. Gipe P K. Rotation, solvation, and hydrogen bonding of aqueous ammonium ion. J Am Chem Soc, 1986, 108: 1088-1089

20 Kanan S M, Tze W T Y, Tripp C P. Method to double the surface concentration and control the orientation of adsorbed (3-aminopropyl) dimethylethoxysilane on silica powders and glass slides. Langmuir, 2002, 18: 6623-6227

21 Mckittrick M W, Jones C W. Toward single-site functional materials: Preparation of amine-functionalized surfaces exhibiting site-isolated behavior. Chem Mater, 2003, 15: 1132-1139

22 Inoue K, Ono Y, Kanekiyo Y, et al. Facile preparation of robust organic gels by cross-link of a sugar-integrated gelator by toluene-2,4diisocyanate. Chem Lett, 1999, 28: 225-226

23 Sayari A, Han B H, Yang Y. Simple synthesis route to monodispersed SBA-15 silica rods. J Am Chem Soc, 2004, 126: 14348-14349

24 Escax V, Delahaye E, Clerc M I, et al. Modifying the porosity of SBA-15 silicas by post-synthesis basic treatments. Microporous Mesoporous Mat, 2007, 102: 234-241

25 Gao Q, Xu W J, Xu Y, et al. Amino acid adsorption on mesoporous materials influence of types of amino acids, modification of mesoporous materials, and solution conditions. J Phys Chem B, 2008, 112: 2261-2267

26 Chantarasiri N, Chulamanee C, Mananunsap T, et al. Thermally stable metal-containing polyureas from hexadentate schiff base metal complexes and diisocyanates. Polym Degrad Stabil, 2004, 86: 505-513

27 Song S W, Hidajat K, Kawi S. Functionalized SBA-15 materials as carriers for controlled drug delivery: Influence of surface properties on matrix-drug interactions. Langmuir, 2005, 21: 9568-9575

28 Hench L L, West J K. The sol-gel process. Chem Rev, 1990, 90: 33-72

Open Access This article is distributed under the terms of the Creative Commons Attribution License which permits any use, distribution, and reproduction in any medium, provided the original author(s) and source are credited. 